\title{
Stimulating the Intrinsic Motivation of Art Major Students in Oral English Learning
}

\author{
$\mathrm{Yu} \mathrm{Hu} \mathbf{u}^{*}$ \\ Faculty of Education and Languages, The SEGi University of Malaysia, Malaysia \\ *Corresponding author: Yu Hu, 2959877415@qq.com
}

Copyright: ( $) 2022$ Author(s). This is an open-access article distributed under the terms of the Creative Commons Attribution License (CC BY 4.0), permitting distribution and reproduction in any medium, provided the original work is cited.

\begin{abstract}
Intrinsic motivation plays a vital role in students' desire in learning oral English. This paper introduces the current situation of oral English teaching and learning in colleges, followed by explaining the reasons why art major students lack motivation in oral English learning. It is suggested that intrinsic motivation promotes students to hold a high interest toward learning and the acquisition of knowledge as well as enables students to achieve autonomous learning. Finally, practical suggestions for stimulating the intrinsic motivation of art major students in oral English learning are proposed.
\end{abstract}

Keywords: Art major students; Intrinsic motivation; Oral English learning

Online publication: January 20, 2022

\section{Introduction}

Along with the growing impact of globalization, China is in the high demand of communication with other countries in various aspects ${ }^{[1]}$. English, as a global language, plays an essential role in many ways, and oral English especially is in high demand in cultural exchange and the field of economy. However, in China, English teaching in colleges generally cannot meet the high demand of English spoken talents from the society ${ }^{[2]}$. Students majoring in art tend to solely focus on their major as they are doing what they love, with high expectations to succeed in this field. Therefore, these students show reluctance in learning oral English as they hardly see the connection between art and English. This study aims to discuss how to effectively stimulate art major students' intrinsic motivation in learning oral English.

\section{Background}

\subsection{The situation of English teaching in colleges}

In China, English is a compulsory course in colleges. All students have to take this course and pass the test so that they can graduate with a degree. The current English teaching in colleges is still test-centered and teacher-centered [3]. Although the importance of learning English has been acknowledged, and China's Ministry of Education (MOE) has pointed out that English teaching in colleges should emphasize more on listening and speaking rather than reading comprehension, the teaching of oral English in the colleges is still unsatisfactory ${ }^{[3]}$. English teaching in colleges has gone through decades of reform, and English teachers have been encouraged to integrate various teaching approaches and methods into their practice in order to improve students' speaking skills; in addition, multimedia, images, videos, etc. are popularly used in classes ${ }^{[1]}$. Yet, the performance of students in oral English hardly meets the expectation. 


\subsection{The situation of oral English learning among students majoring in art}

For art major students, the entrance requirements are lower than those of other majors. There are two entrance examinations for these students: a grueling college entrance examination that is held every summer across the country, and painting; namely, a culture test and major test. Majoring in art is very costly, and the tuition fees are also higher than other majors. Many of these students come from wealthy families, and their parents are very supportive of their children's learning as witnessed by the provision of expensive smartphones, laptops, and other advanced electronic devices for more access to information. Hence, many of them are not too worried if they do not find a satisfactory job in the future as they have a wealthy family background. The reality here is that some students major in art because their scores do not meet the requirements of other majors, thereby leaving them no option to choose from; on the other hand, some students major in art because they have great enthusiasm for painting and are likely care about nothing else. In these cases, students majoring in art are not very willing to learn oral English as they view English and art as two very different majors.

\section{Intrinsic motivation}

\subsection{Concept of intrinsic motivation}

Motivation refers to the act of giving people reasons for doing something to achieve a particular goal. From a psychological perspective, motivation can be divided into intrinsic motivation and extrinsic motivation. Intrinsic motivation refers to the drive that leads to a certain behavior in order to satisfy a purpose, in which it is induced by internal factors. Students' intrinsic motivation, such as their interests, desires, and expectations for improving their skills in learning, leads to learner autonomy. Intrinsic motivation is different from extrinsic motivation, yet they are closely associated. Extrinsic motivation is the opposite, in which it is derived from the external environment, resulting in the intention to satisfy a purpose. Ryan and Edward suggested that intrinsic motivation is the key for the desire to acquire knowledge; however, extrinsic motivation can also be transferred into intrinsic motivation within the guidance of teachers or relevant parties ${ }^{[4]}$.

\subsection{Connection between intrinsic motivation and language learning}

Intrinsic motivation is a very important internal factor that has profound influence on students' second language acquisition. Zhang suggested that there are two kinds of factors that affect students' second language acquisition, which are internal factors and external factors ${ }^{[5]}$. Internal factors such as students' attitude, motivation, and personality are considered as individual differences. When teachers cultivate students based on individual differences, internal factors shall be taken into consideration. The effect that internal factors have toward second language acquisition mainly refers to the students' internal physiological mechanism and reaction toward second language acquisition. Studies have shown that intrinsic motivation promotes students to engage in learning activities, which enables students to actively and spontaneously commit to learning ${ }^{[5]}$. It is commonly acknowledged that intrinsic motivation is one of the most important and essential factors that influence students' English proficiency or language achievements ${ }^{[4]}$. It is important for teachers to realize the role of intrinsic motivation in students' oral English learning and to make full use of it.

\section{Stimulating the intrinsic motivation of art major students in oral English learning}

Various teaching methods are encouraged to be applied in oral English teaching, in order to explore the possibility of teaching art students oral English in accordance with their passion. A few practical and possible ways to stimulate art students' intrinsic motivation in oral English learning have been proposed. 


\subsection{Using authentic videos}

With the rapid development of science and technology, every classroom is equipped with advanced teaching technologies, such as computers and visualizers. Wi-Fi is available throughout the campus, and it also can be accessed in classrooms. Many innovations have been introduced into education, especially in language teaching. Wang suggested that teachers should create various learning opportunities for students so that their learning opportunities can be maximized ${ }^{[6]}$. Language teachers, especially English teachers, are using authentic videos in classrooms to create a better teaching-learning platform, which may facilitate both teaching and learning as well as encourage students to achieve autonomous learning and interaction [6].

Authentic videos consist of images and conversations, with more vivid expressions of language. The use of authentic videos is indeed an effective way to add diversity to the teaching method, in order to create a better teaching-learning platform ${ }^{[7]}$. With authentic videos, students are placed in real situations to experience how people communicate in English. More importantly, authentic videos add fun to teaching; thus, students would show more interest in class. The advantages of using authentic video in language teaching has been studied and proven. The most important thing is for the teachers to use authentic videos wisely to meet the teaching objectives.

\subsection{Cultivating students' perception of oral English learning}

If teachers are able to help students align their beliefs or values with oral English learning, the students' intrinsic motivation would improve; in addition, the teaching and learning process would be facilitated. Firstly, teachers need to build a connection between oral English learning and the major so that the importance of learning oral English can be acknowledged. "What is the use of learning oral English?" This is a common question shared by most art students. In order to improve their intrinsic motivation, art students need to realize why they need to strive to learn oral English. Secondly, teachers need to guide students to accept that learning oral English can lead them to see a bigger world. For instance, if ever they have an opportunity to meet or speak with foreign art experts or masters, oral fluency in English may provide a lifetime opportunity to these students to learn from the best by exchanging art experiences with these experts. In that way, the students understanding of art will be brought to a higher level, which would add more possibilities for fine job offers. Therefore, learning with a purpose helps students to set goals with intrinsic motivation in English learning. It is important for teachers to help students see oral fluency in English as a "shiny golden ticket," which leads to more opportunities and possibilities in the future.

\subsection{Combining the art major with oral English teaching}

In order to stimulate students' intrinsic motivation in oral English learning, majors can be merged with language teaching. Students major in art mostly because their interest is in painting; in that case, if their interest can be extended further to oral English learning, the learning result can be improved. For instance, if the teaching objective in a lesson is for students to share about their favorite season, the teacher can set a task that requires students to make a poster that reflects the characteristics of their favorite season or things that best represent the season, and then list out the key features in English about this season so that the students can use the poster to present later. In that way, students are scaffolding and learning English while doing something they love - art. This would deepen their memory of the usage of English, and it would be easier for them to speak in English.

\section{Conclusion}

In China, the current English teaching in colleges is test-centered, and the goal of learning English for art 
students is mainly to pass the exam and obtain a degree. The objectives of English teaching in colleges mainly emphasize on reading and writing, without much attention to oral English. Hance, art students are demotivated to develop their skills in oral English, which means their intrinsic motivation in learning oral English is extremely low. However, they need to improve their oral English skills as the world is in high demand for fluent English-speaking talents. English teachers in colleges need to be aware of the importance of students' intrinsic motivation in oral English learning. Although intrinsic motivation is a stronger motivator than extrinsic motivation, extrinsic motivation can easily affect intrinsic motivation or even replace it. Teachers need to be aware of the factors from the external environment and make the utmost of those factors to transfer extrinsic motivation into intrinsic motivation so as to drive students to motivate themselves.

\section{Disclosure statement}

The author declares that there is no conflict of interest.

\section{References}

[1] Liu Q, 2019, Enlightenment of the Initiative on College English Teaching. Journal of Zhaotong University, 41(2): 103-106.

[2] Wu JH, 2014, Research on College English Teacher's Attitude towards Language in EFL Classroom. Journal of Foreign Language Teaching, 2014(02): 55-56.

[3] Zhao ZT, 2012, EFL Teaching and Reform in China's Tertiary Education. Journal of Language Teaching and Research, 3(6): 1098-1104.

[4] Ryan RM, Deci EL, 2000, Intrinsic and Extrinsic Motivations: Classic Definitions and New Directions. Contemporary Educational Psychology, 25(1): 54-67.

[5] Zhang JY, 2021, 2nd International Conference on Humanities, Arts, and Social Sciences (HASS 2021), October 23, 2021: An Overview of Motivation in Second Language Acquisition. Philosophy and Humanities. DOI: 10.26914/c.cnkihy.2021.030096

[6] Wang Z, 2015, An Analysis on the Use of Video Materials in College English Teaching in China. International Journal of English Language Teaching, 2(1): 23-28.

[7] Sherman J, 2003, Using Authentic Video in the Language Classroom, Cambridge University Press, Cambridge. 